\title{
6
}

\section{BENTUK KESANTUNAN BERBAHASA DALAM WACANA DIALOG KETOPRAK SAPTA MANDALA LAKON BABAD ALAS MENTAOK}

\author{
Agung Pramujiono
}

\begin{abstract}
This study aimed at describing and explaining the phenomenon of linguistic politeness in dialogue discourse in Ketoprak Sapta Mandala of in the play of Babad Alas Mentaok. This phenomenon needs to be studied because politeness in this discourse is unique, particularly in the selection of forms and politenesss trategies. The study used the Politeness Theory of Brown and Levinson (1987) with ethnopragmatic perspectives. Ethnopragmatics is an interdisciplinary study of Pragmatics and Ethnographic of Communication. Data were taken from the recording of Ketoprak Sapta Mandala "Ratu Kidul" episode of "Babad Alas Mentaok" drama series by Fajar which is converted into a digital format in website of jamansemono.com. It was then analyzed by using descriptive analysis following the interactive model of Miles and Huberman. Based on the analysis of data, it can be concluded that utterances representing forms of politeness can be broken down into three categories: declarative (SUBDek), interrogative (SUBInt), and imperative (SUBImp) modes. SUBDek was realized in various forms of speech acts including (1) assertive speech acts: notifying and stating; and (2) expressives: thanking, expressing happiness, apologizing, praising, and criticizing. SUBInt was realized indirective speech acts, such as requesting information, confirming, and asking for permission. SUBImp realized indirective speech acts, for instance giving commands, allowing, probibiting, and inviting. The politeness strategies used in the play discourse include direct strategies; positive politeness strategies with sub-strategies (1) giving attention, (2) giving praise, and (3) using a group marker; negative politeness strategies with sub-strategies(1) using speech of respect, (2) using indirect speech, and (3) using a variety of manners; and off-record/indirect strategies under taken by (1) using narrative strategies and (2) using implied speech. The use of narrative strategies as the indirect strategy constitutes a finding that can be used to complement the indirect sub-strategy proposed by Brown and Levinson (1987).
\end{abstract}

Keywords: politeness strategies, dialogue discourse, ethnopragmatics

\section{PENDAHULUAN}

Ketoprak merupakan salah satu jenis kesenian tradional yang banyak digemari oleh masyarakat Jawa, khususnya di wilayah Jawa Tengah dan sebagian Jawa Timur bagian barat. Aziz (2012) menyatakan bahwa dalam jagad kesenian negeri ini, ketoprak menjadi salah satu ikon penting yang menyuguhkan lakon cerita tentang kehidupan dan sejarah kemanusiaan. Ketoprak menjadi media pertunjukan untuk mementaskan cerita dalam labirin kehidupan dan kearifan Jawa. Dari pandangan Aziz (2012) dapat dicatat beberapa hal penting berkaitan dengan ketoprak. Sebagai ikon penting, ketoprak merupakan identitas suatu masyarakat tertentu, yaitu Jawa. Sebagai media pertunjukan, ketoprak menjadi wahana pembelajaran, penyampaian pesan, dan pelestarian nilai-nilai kearifan lokal bagi masyarakat Jawa.

Sebagai salah satu jenis seni pertunjukan tradisional, ketoprak memunyai karakteristik tersendiri. Pertama, dilihat dari lakon yang 
dimainkan. Ketoprak menyajikan cerita tokoh dan sejarah Jawa khususnya dan hikayat dari Persia. Cerita tersebut mengandung suri teladan dan hikmah yang dapat dipetik untuk membangun kepribadian manusia (Dhave, 2011). Kedua, dalam ketoprak diselipkan humor (daghelan) sebagai hiburan dan tembang-tembang pengiring yang mengandung nilai filosofi tinggi. Ketiga, dilihat dari aspek kewacanaan ketoprak menyajikan wacana monolog dan dialog dalam bahasa Jawa berikut tataran bahasanya (undha usuk). Dari aspek wacana, khususnya wacana dialog ketoprak mengandung fenomena kebahasaan yang menarik untuk dikaji berkaitan dengan upaya menjaga muka paraga (tokoh).

Sebagai interaksi interpersonal, wacana dialog dalam ketoprak melibatkan tokoh-tokoh sebagai interaktan dalam dialog. Tokoh-tokoh sebagai interaktan dalam dialog memunyai latar belakang sosial yang berbeda. Secara dikotomi latar belakang sosial tokoh tersebut dapat dibedakan atas kelompok bangsawan dengan status sosial tinggi dan punggawa atau rakyat jelata dengan stasus sosial rendah.

Interaksi interpersonal dalam ketoprak merupakan sebuah interaksi sosial antartokoh. Sebagai interaksi sosial, dialog dalam ketoprak seperti halnya bentuk aktivitas sosial yang lain, menunjukkan suatu aksi dan interaksi dari partisipasi anggota suatu masyarakat sebagai sebuah perwujudan interaksi simbolik. Dalam konteks ini, anggota masyarakat tersebut berusaha untuk saling memahami satu dengan yang lain. Hal itu tampak dari upaya partisipan menjaga kelangsungan percakapan dengan ujaran yang tepat dan koheren (van Dijk, 1985:2).

Dalam melakukan interaksi intepersonal, interaktan akan berusaha untuk menjaga dan menyelamatkan muka, baik muka penutur $(\mathrm{Pn})$ maupun mitra petutur $(\mathrm{Pt})$ (Brown dan Levinson, 1987; Scollon dan Scollon, 2001). Karena itu dalam melakukan tindak tutur, tokoh-tokoh dalam ketoprak perlu memilih bentuk ujaran dan strategi kesantunan untuk menjaga muka sehingga ujaran mereka menjadi santun. Dengan demikian dapat dibangun kehidupan yang harmonis dan terhindar dari friksi-friksi. Hal ini sejalan dengan konsep kesantunan yang dikemukakan oleh Leech (1993), bahwa kesantunan merupakan suatu strategi untuk menghindari konflik, menjaga, dan mempertahankan rasa hormat sehingga terbangun harmoni.

Pemilihan bentuk kesantunan dalam wacana ketoprak merupakan fenomena yang menarik dan unik sehingga perlu dilakukan penelitian terhadap fenomena tersebut. Fokus penelitian ini dirumuskan dalam pertanyaan penelitian sebagai berikut. Bagaimanakah bentuk ujaran yang merepresentasikan kesantunan berbahasa dalam wacana dialog Ketoprak Sapta Mandala lakon Babad Alas Mentaok?

Berkaitan dengan bentuk kesantunan, Watts (2003) membedakan bentuk verbal yang mengindikasikan kesantunan menjadi tiga, yaitu ujaran formulaik, ujaran ritual, dan ujaran semiformulaik. Watts kemudian merinci bentuk-bentuk lingual yang digunakan Pn dalam mengekspresikan kesantunan berbahasa sebagai 
berikut. (1) Bentuk sapaan yang meliputi (a) nama diri, (b) gelar kehormatan, dan (c) gelar akademik; (2) Bentuk ujaran yang digunakan untuk menyatakan terima kasih dan permintaan maaf; (3) Bentuk ujaran yang digunakan sebagai ritual perpisahan; (4) Bentuk berpagar dengan berbagai ragam ekspresinya; (5) Bentuk penanda solidaritas; (6) Bentuk lingual yang berfungsi mendorong kelangsungan tindak tutur, misalnya tentu saja, jelasnya; dan (7) Bentuk modalitas yang digunakan dalam ekspresi tertentu, misalnya bolehkah, dapatkahsebagai piranti untuk mengekspresikan ketidaklangsungan suatu ujaran.

Dalam wacana dialog, berbagai bentuk verbal kesantunan tersebut diwujudkan dalam struktur kalimat dengan modus imperatif, interogatif, dan deklaratif. Kalimat dengan ketiga modus tersebut dapat merealisasikan tindak tutur direktif, asertif, ekspresif, komisif, dan deklaratif bergantung kepada konteks ujaran.

Modus merupakan kategori gramatikal dalam bentuk verba yang mengungkapkan suasana psikologis perbuatan menurut tafsiran pembicara atau sikap pembicara tentang apa yang diucapkannya (Kridalaksana, 1984). Secara sintaktik, modus suatu kalimat ditandai oleh sebutannya, yaitu yang berisi titik informasi baru tentang topik kalimat itu (Halim, 1984). Lebih lanjut dikemukakan oleh Halim bahwa kalimat memunyai modus deklaratif, naratif, optatif, negatif, imperatif, interogatif, dan lain-lain. Dari berbagai jenis modus kalimat tersebut, Halim membatasi kajiannya pada tiga jenis modus yaitu deklaratif, interogatif, dan imperatif. Apa yang dilakukan Halim tersebut sejalan dengan pandangan Fairclough. Fairclough menyatakan dari berbagai jenis modus ada tiga yang dianggap utama, yaitu modus deklaratif, bentuk tanya (interogatif), dan imperatif.

Modus deklaratif ditandai dengan adanya subjek (S) yang diikuti oleh verba sebagai predikat $(\mathrm{P})$. Posisi $\mathrm{S}$ sebagai penutur memberikan informasi sedangkan posisi petutur menerima informasi (Fairclough, 1989:126). Rahardi (2000:73) menyatakan bahwa kalimat deklaratif mengandung maksud memberitahukan suatu hal atau suatu kejadian kepada mitra tutur. Hal ini sejalan dengan pandangan Alwi, dkk. (2000:352) yang menyatakan bahwa dalam pemakaian bahasa, bentuk kalimat deklaratif umumnya digunakan oleh pembicara/penulis untuk membuat pernyataan sehingga isinya merupakan berita bagi pendengar atau pembacanya. Kalimat deklaratif mempunyai ciri prosodi berintonasi menurun/jatuh pada suku terakhir dengan pola 221t, 231t, dan 211t (Halim, 1984:108).

Dalam kalimat bermodus interogatif, penutur menanyakan sesuatu kepada mitra tuturnya dan mitra tutur memberikan informasi. Berdasarkan tipe gramatikalnya, Fairclough (1989:126) membedakan kalimat bermodus interogatif menjadi dua, yaitu kalimat interogatif dengan tipe wh-questions (who, what, when, where, why, which, dan how) dan tipe yes-no answer. Kalimat bermodus deklaratif dapat berubah menjadi kalimat bermodus interogatif dengan 
memberikan kata tanya apa atau apakah dan mengubah menjadi intonasi tanya.

Menurut Alwi, dkk. (2000:357), dalam bahasa Indonesia terdapat empat cara untuk mewujudkan kalimat bermodus interogatif. (1) dengan membalikkan urutan kalimat, (2) dengan menggunakan kata apa, (3) dengan menggunakan kata bukan(kah) atau tidak(kah), dan (4) dengan mengubah intonasi kalimat menjadi naik. Kalimat bermodus interogatif memunyai ciri prosodi berintonasi menurun/jatuh pada suku kata terakhir dengan pola 231t dan 211t (Halim, 1984:112-113).

Kalimat bermodus imperatif adalah kalimat yang mengandung maksud memerintah atau meminta agar mitra tutur melakukan sesuatu seperti yang diinginkan oleh penutur (Rahardi, 2000). Menurut Fairclough (1989), kalimat bermodus imperatif pada umumnya tidak memunyai subjek atau menggunakan kata ganti kamu sebagai S.

Dalam bahasa Indonesia, kalimat bermodus imperatif memunyai empat ciri (Alwi, dkk., 2000). Pertama, intonasi ditandai dengan nada rendah di akhir ujaran; kedua, pemakaian partikel penegas, penghalus, dan kata tugas ajakan, harapan, permohonan, dan larangan; ketiga, bersusun inversi; dan keempat, pelaku tindakan tidak selalu terungkap. Lebih lanjut, Alwi, dkk. (2000), berdasarkan isinya, membedakan kalimat bermodus imperatif menjadi enam jenis. (1) perintah/suruhan, jika pembicara menyuruh lawan bicaranya berbuat sesuatu, (2) perintah halus, jika pembicara tampaknya tidak memerintah, tetapi menyuruh mencoba atau mempersilakan lawan bicara sudi berbuat sesuatu, (3) permohonan, jika pembicara demi kepentingannya, minta lawan bicara berbuat sesuatu, (4) ajakan atau harapan, jika pembicara mengajak atau berharap lawan bicara berbuat sesuatu, (5) larangan, jika pembicara menyuruh jangan dilakukan sesuatu, dan (6) pembiaran, jika pembicara minta agar jangan dilarang. Kalimat bermodus imperatif memunyai ciri prosodi berintonasi jatuh pada suku kata terakhir. Pola intonasinya adalah $231 \mathrm{t}$ dan 211t (Halim, 1984:114).

\section{DASAR TEORITIS}

Sesuai dengan fokus penelitian, penelitian ini menggunakan pendekatan kualitatif. Dengan mengacu karakteristik penelitian kualitatif yang dikemukakan oleh Bogdan dan Biklen (1998) dan Moleong (1995), penggunaan pendekatan kualitatif dalam penelitian ini berdasarkan alasan (1) analisis data dilakukan secara induktif, berdasarkan fenomena yang spesifik kemudian dianalisis dan ditarik suatu simpulan, (2) penelitian ini bertujuan mendeskripsikan fenomena kesantunan berbahasa dalam wacana dialog ketoprak sehingga sesuai dengan karakteristik penelitian kualitatif yang berupaya mendeskripsikan suatu fenomena, dan (3) dalam penelitian ini, peneliti berperan sebagai instrumen utama.

Dalam penelitianini, kesantunan berbahasa dalam wacana dialog ketoprak dideskripsikan dan dianalisis dari perspektif etnopragmatik. Digunakan ancangan tersebut karena interaksi verbal antarinteraktan dalam 
dialog ketoprak tidak dapat dipisahkan dari konteks sosiosituasional dan sosiokultural yang melatarinya. Dalam konteks tersebut, pemakaian bahasa dalam wacana dialog ketoprak dipandang sebagai tindak tutur yang merupakan unit terkecil dari interaksi verbal dalam suatu peristiwa tutur dalam konteks sosiosituasional dan sosiokultural tertentu dengan latar yang bersifat alamiah.

Sesuai dengan fokus penelitian, data penelitian ini adalah ujaran tokoh yang merepresentasikan bentuk. Data tersebut ditunjang dengan catatan lapangan berupa gambaran konteks/komponen tutur seperti yang dikemukakan dalam etnografi komunikasi sebagai SPEAKING (Hymes, 1974; SavilleTroike, 1994; Duranti, 1997; dan Keating, 2007). Sumber data penelitian ini adalah dialog antartokoh dalam Ketoprak Sapta Mandala lakon Babad Alas Mentaok. Lakon Ketoprak tersebut diambil dari seri lakon Ratu Kidul yang terdiri atas 16 episode. Lakon Babad Mentaok terdiri atas 4 episode. Rekaman tersebut diunduh dari laman: jamansemono.com yang diubah menjadi format digital dari rekaman Fajar dengan seri 425.

Dalam penelitian ini pengumpulan data dilakukan dengan menggunakan dua cara, yaitu menggunakan metode simak teknik catat (Sudaryanto, 1993) dan observasi nonpartisipasi (Kuswarno, 2008). Metode simak digunakan untuk mengumpulkan data berupa bentuk kesantunan yang digunakan dalam wacana dialog Ketoprak Sapta Mandala lakon Babad Alas Mentao, sedangkan observasi nonpartisipasi digunakan untuk memperoleh data penunjang berupa catatan lapangan tentang konteks ujaran. Teknik analisis data yang digunakan dalam penelitian ini adalahteknik deskriptif dengan mengikuti model interaktif (Miles dan Huberman, 1992). Dengan penggunaan teknik deskriptif akan dideskripsikan dan dijelaskan secara detil fenomena-fenomena yang menjadi fokus penelitian (1) bentuk ujaran yang merepresentasikan bentuk dan (2) strategi kesantunan yang digunakan oleh tokoh dalam wacana dialog Ketoprak Sapta Mandala lakon Babad Alas Mentaok.

Dalam menganalisis bentuk ujaran yang merepresentasikan kesantunan akan dideskripsikan penggunaan ujaran dengan modus deklaratif, interogatif, dan direktif dalam tindak ilokusi asertif, direktif, dan ekspresif (Leech, 1997). Dalam ujaran tersebut akan dianalisis peranti kesantunan linguistik yang meliputi (1) penggunaan bentuk sapaan, (2) penggunaan kata ganti, (3) penggunaan gelar, (4) penggunaan modalitas, dan (5) penggunaan ungkapan kesantunan.

\section{HASIL KAJIAN DAN PEMBAHASAN}

\section{Bentuk Ujaran yang Merepresentasikan}

\section{Kesantunan Berbahasa dalam Dialog}

Ketoprak Sapta Mandala Lakon Babad Alas

\section{Mentaok}

Hasil penelitian berkaitan dengan bentuk ujaran yang merepresentasikan kesantunan berbahasa dibedakan atas bentuk kesantunan ujaran bermodus deklaratif (SUBDek), bentuk kesantunan ujaran bermodus interogatif 
(SUBInt), dan bentuk kesantunan ujaran bermodus imperatif (SUBImp). Masing-masing modus ujaran dan realisasi tindak tutur dipaparkan sebagai berikut.

\subsection{Bentuk SUBDek}

Ujaran bermodus deklaratif dalam bahasa Indonesia memunyai makna memberitahukan sesuatu kepada Pt (Rahardi, 2000 dan Alwi, dkk., 2000). Bentuk SUBDek dalam wacana dialog Ketoprak Sapta Mandala Lakon babad Alas Mentaok direalisasikan dalam berbagai bentuk tindak tutur. Keragaman tindak tutur tersebut meliputi (1) tindak tutur asertif memberitahukan dan menyatakan; dan (2) tindak tutur ekspresif menyampaikan terima kasih, menyatakan rasa senang, meminta maaf, memuji, dan mengkritik. Masing-masing realisasi tindak tutur disajikan pada paparan berikut.

\subsubsection{Bentuk SUBDek dalam Tindak Tutur Asertif}

Tindak tutur asertif adalah tindak tutur yang berfungsi untuk menyatakan sesuatu yang dapat dinilai kebenarannya (Leech, 1993). Bentuk SUBDek dalam tindak tutur asertif pada wacana dialog Ketoprak Sapta Mandala lakon Babad Alas Mentaok meliputi tindak tutur asertif memberitahukan dan menyatakan. Bentuk kesantunan masing-masing tindak tutur dipaparkan sebagai berikut.

1) Bentuk SUBDek dalam Tindak Tutur Asertif Memberitahukan
Dalam wacana dialog Ketoprak Sapta Mandala lakon Babad Alas Mentaok, bentuk SUBDek dalam tindak tutur asertif memberitahukan dapat dilihat pada data berikut.

$$
\begin{gathered}
\text { KJM : Orak Di... jan-jane mawon Adi } \\
\text { Pemanahan mrene iki yen ana } \\
\text { rembug... rembug napa? (1) } \\
\text { (Tidak Di... sebenarnya Adi } \\
\text { Pemanahan ke sini ini ada perlu } \\
\text { apa?) } \\
\text { KP : Niku ngoten Kang... Mila kula } \\
\text { kalih keng Putra Danang } \\
\text { Sutawijaya kumudu-kudu lan } \\
\text { keraya-raya sowan Kakang nikijane } \\
\text { nggih mung ajeng nyuwun rembag.(2) } \\
\text { Kalih anu... mestine nggih kalih } \\
\text { nyuwun iguh pratikel. (3) } \\
\text { (Begini Kang... Saya dan Putramu } \\
\text { Danang Sutawijaya bersusah } \\
\text { payah menemui Kakang karena } \\
\text { ada yang perlu dibicarakan. Dan } \\
\text { sebenarnya juga mau minta } \\
\text { pertimbangan) (BAM.1.22-23) }
\end{gathered}
$$

[2] KR : Priye anggonira ngayahi jejibahan K ngembat praja Samodra Kidul Mbok Rara? (1)

(Bagaimana dengan tugasmu mengatur kerajaan Samodra Kidul Mbok Rara)

MR : Kanjeng Ratu pepundhen kula... $\mathrm{K}$ miturut pelapurane abdi dalem ingkang pinuji njagi Kraton Kidul mboten wonten bebaya ingkang saget mlebet Kanjeng Ratu. (2)

(Kanjeng Ratu yang saya hormati... menurut laporan abdi yang menjada Kraton Kidul tidak akan ada marabahaya yang bisa masuk Kanjeng Ratu) (BAM.3.47-48) 
Pada [1] konteks ujarannya adalah Ki Juru Mertani (KJM) menanyakan kepada Ki Pemanahan (KP) tujuan mereka berkunjung ke rumahnya. KJM adalah saudara seperguruan tertua KP. Bentuk ujaran bermodus deklaratif dalam tindak tutur ilokusi asertif memberitahukan dapat dilihat pada kalimat (2), Niku ngoten Kang... Mila kula kalih keng Putra Danang Sutawijaya kumudu-kudu lan keraya-raya sowan Kakang niki jane nggib mung ajeng nyunun rembag. Kesantunan ujaran pada kalimat (2) ditandai dengan penggunaan pilihan ragam krama dan penggunaan bentuk sapaan Kang yang menunjukkan keakraban Pn dengan Pt. Dalam kalimat (2) dapat diketahui Pn memberitahukan tujuan kedatangannya itu untuk membicarakan suatu perkara. Ujaran KP tersebut merupakan respon dari pertanyaan KJM, Orak Di... jan-jane mawon Adi Pemanahan mrene iki yen ana rembug.... rembug napa? (1). Pada kalimat inisiasi, tersebut tampak kalau KJM juga sangat menghormati KP. Hal ini tampak dari digunakannya bentuk sapaan, $A d i$ dan digunakannya ragam krama oleh KJM. Dengan demikian ujaran tersebut merupakan ujaran yang santun.

Konteks ujaran [2] adalah Kanjeng Ratu Kidul (KRK) bertanya kepada Mbok Rara Kidul (MRK) tentang tugasnya mengatur pemerintahan di Kerajaan Samodra Kidul. Bentuk ujaran bermodus deklaratif dalam tindak tutur ilokusi asertif memberitahukan yang merepresentasikan kesantunan dapat dilihat pada (2), Kanjeng Ratu pepundhen kula... miturut pelapurane abdi dalem ingkang pinuji njagi Kraton
Kidul mboten wonten bebaya ingkang saget mlebet Kanjeng Ratu. Kesantunan berbahasa dalam kalimat (2) ditandai dengan penggunaan bentuk sapaan yang menyatakan penghormatan, Kanjeng Ratu pepundhen kula dan pemilihan ragam krama.

2) Bentuk SUBDek dalam Tindak Tutur Asertif Menyatakan

Dalam wacana dialog Ketoprak Sapta Mandala lakon Babad Alas Mentaok, bentuk SUBDek dalam tindak tutur asertif menyatakan dapat dilihat pada data berikut.

KJM : Pun lek niku tenan sakniki
awake dhewe ditakoni
malih! Aku ki wani
tanggung jawab ora karo
tumindhakku? (1)

(Sudah kalau memang demikian, sekarang dirinya ditanya kembali. Saya ini berani bertanggung jawab tidak terhadap perbuatanku)

DS : Lha nggih wani ta Wo... terang awakipun piyambak. dawah leres tosipun. (2)

(Lha tentu berani Wo. Jelas kita berada di pihak yang benar.)

KJM : Pun niku Angger wani tenan? (3) Adi Pemanahan nggih mboten wedi? (4) (Sudah begitu, Ananda benar-benar berani? Adi Pemanahan juga tidak takut?)

$\mathrm{KP}$ : Lha sing dipun wedheni napa Kang.(5)

(Lha yang ditakuti apa Kang.) (BAM.1.51-54) 
[4] KRK : Menawi Panjenengan wani... eh... kula trimah kawon Raden. (1)

(Kalau Anda berani, eh... lebih baik saya mengalah Raden.)

DS : Kanjeng Ratu... trimah kawon menika sejatosipun mboten kawon Kanjeng Ratu.... (2) (Kanjeng Ratu.... mengalah itu sebenarnya tidak kalah Kanjeng Ratu.) (BAM.6.60-61)

Pada [3], konteks ujarannya adalah KJM berusaha memastikan apakah Danang Sutawijaya (DS) dan KP teguh pendirian pada keputusan yang sudah diambil. Bentuk ujaran bermodus deklaratif dalam tindak tutur ilokusi asertif menyatakan yang merepresentasikan kesantunan dapat dilihat pada (2), Lha nggih wani ta $W o$... terang awakipun piyambak dawab leres tosipun dan pada (5), Lha sing dipun wedheni napa Kang. Ujaran (2) merupakan respon DS terhadap pertanyaan KJM (1). Kesantunan ujaran (2) ditandai dengan penggunaan ragam krama oleh DS dan penggunaan bentuk sapaan $W_{0}$ yang menunjukkan kedekatan hubungan antara Pn dengan Pt. Kalimat (5) merupakan respon KP terhadap pertanyaan KJM (4), Adi Pemanaban nggih mboten wedi? Kesantunan berbahasa dalam ujaran bermodus deklaratif tersebut ditandai dengan penggunaan bentuk sapaan Kang dan pemilihan ragam krama oleh KP. Hal ini menunjukkan bahwa KP sangat menghormati KJM.

\subsubsection{Bentuk SUBDek dalam Tindak Tutur Ekspresif}

Tindak tutur ekspresif adalah tindak tutur yang berfungsi untuk menyatakan sesuatu yang mengungkapkan atau mencerminkan sikap psikologis Pn terhadap keadaan yang tersirat dalam ilokusi (Leech, 1993). Bentuk SUBDek dalam tindak tutur ekspresif dalam wacana dialog Ketoprak Sapta Mandala lakon babad Alas Mentaok meliputi tindak tutur ekspresif menyampaikan terima kasih, menyatakan rasa senang, meminta maaf, memuji, dan mengkritik

Bentuk kesantunan masing-masing tindak tutur dipaparkan sebagai berikut.

1) Bentuk SUBDek dalam Tindak Tutur Ekspresif Menyampaikan Terima Kasih

Dalam wacana dialog Ketoprak Sapta Mandala lakon Babad Alas Mentaok, bentuk SUBDek dalam tindak tutur ekspresif menyampaikan terima kasih dapat dilihat pada data berikut.

[5] KRK : Ah... nedha nrima banget Sira caos peling Ingsun Mbok Rara Kidul.

(1)

(Ah... aku menyampaikan banyak terima kasih kamu sudah mengingatkan aku Mbok Rara Kidul.)

MRK : Injih.... Kanjeng Ratu... ngaturaken bekti mugi konjuk Kanjeng Ratu.... (2) (Iya... Kanjeng Ratu.... menghaturkan sembah bakti semoga berkenan menerima Kanjeng Ratu....) (BAM.3.6-7)

Konteks ujaran [5] adalah KRK menyampaikan terima kasih kepada patihnya 
MRK karena sudah mau mengingatkan ketika dirinya hanyut dalam perasaan karena sedang merasakan jatuh cinta dengan seseorang. Ujaran yang menunjukkan tindak tutur eksprsif menyampaikan terima kasih dapat dilihat pada (1) Ah... nedha nrima banget Sira caos peling Ingsun Mbok Rara Kidul. Kalimat tersebut diujarkan oleh seorang ratu kepada patihnya sehingga menggunakan ragam ngoko. Kesantunan ujaran ditandai dengan penggunaan bentuk sapaan, Sira dan Mbok Rara Kidul. Penggunaan bentuk sapaan tersebut menunjukkan Pn menghormati dan menghargai Pt.

2) Bentuk SUBDek dalam Tindak Tutur Ekspresif Menyatakan Rasa Jengkel

Dalam wacana dialog Ketoprak Sapta Mandala lakon Babad Alas Mentaok, bentuk SUBDek dalam tindak tutur Ekspresif menyatakan rasa jengkel dapat dilihat pada data berikut.

[6] KJM : Lo... lakok Alas Mentaok dereng tamtu diparingke. (1) Niku jalarane niku napa Di? (2)

(Lo... kenapa Alas Mentaok belum jadi diberikan. Itu sebabnya apa Di?)

KP : Lha niku Kang. (3) Nek kula ngrasakne perkara niku ati dadi mangkel Kang. (4)

(Lha itu Kang. Kalau saya merasakan perkara itu hati jadi jengkel, Kang).

KJM : Heh....

KP : Pripun ta... ngendikane Jeng Sultan niku mung didhawubi sabar... mawon.

(5) Dhawube supaya ngenteni titi wancine. (6)

(Bagaimana ya.... katanya Jeng

Sultan itu hanya disuruh bersabar dulu. Sabdanya supaya menanti saat yang tepat) (BAM.1.34-37)

Konteks ujaran [6] adalah KP menyampaikan ketidakpuasan dan kejengkelannya terhadap Sultan Hadiwijaya kepada KJM. Dalam menyampaikan kejengkelannya tersebut, KP tetap memegang tatakrama dan menghargai rajanya. Hal ini dapat dilihat pada penggunaan sapaan Jeng Sultan dan pilihan kata didhawubi. Hal ini dapat dilihat pada kalimat (5) Pripun ta... ngendikane Jeng Sultan nikeu mung didhawubi sabar... mawon dan (6) Dhawube supaya ngenteni titi wancine. Di samping itu penggunaan ragam krama juga menunjukkan kalau KP masih memegang nilai-nilai kesantunan. Meskipun hatinya jengkel, Pn masih tetap mengendalikan dirinya ketika bertutur.

3) Bentuk SUBDek dalam Tindak Tutur Ekspresif Meminta Maaf

Dalam wacana dialog Ketoprak Sapta Mandala lakon Babad Alas Mentaok, bentuk SUBDek dalam tindak tutur ekspresif meminta maaf dapat dilihat pada data berikut.

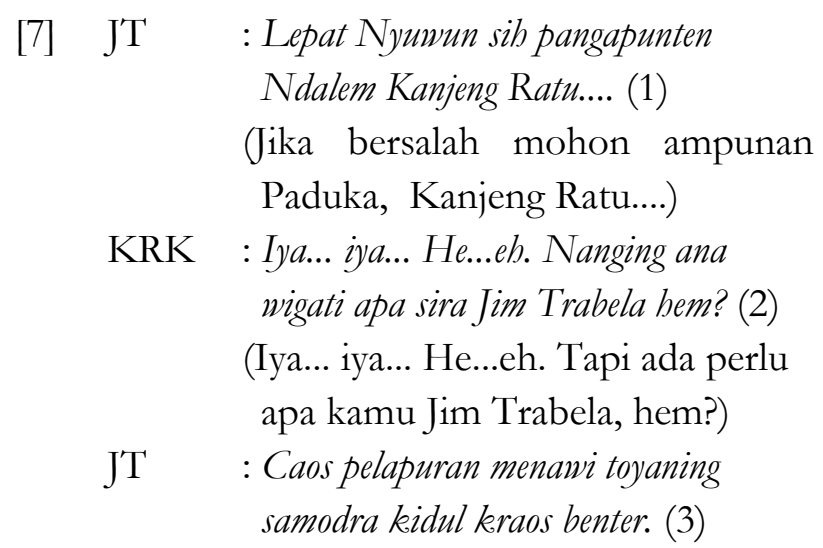

Jurnal Budaya Nusantara Vol. 1 No. 2 | 155 
Malah ing sisit pojok lor wetan ketingal wonten cabya manther.(4) Sumonggo Kanjeng Ratu.... (5) (Memberikan laporan kalua air samodra selatan terasa panas. Malahan di sebelah pojok utara timur terlihat ada cahaya terang. Terserah Paduka Kanjeng Ratu....) (BAM.3.52-54).

[8] KRK : Ob.... Nyumun pangapunten... dados Njenengan ingkang asma Raden Sutawijaya? (1)

(Oh... mohon maaf. Jadi Anda yang bernama Raden Sutawijaya?)

DS : Menapa Kanjeng Ratu Kidul sampun mireng nama kula Kanjeng Ratu? (2)

(Apakah Kanjeng Ratu Kidul sudah mendengar nama saya, Kanjegn Ratu?)

KRK : Namung saking dedongengan kemawon Raden.(3) (Hanya dari cerita saja Raden.) (BAM.5.1618)

Konteks ujaran [7] adalah Jim Trabela (JT) mau menghadap KRK. Karena menghadap tanpa dipanggil sebelumnya, JT merasa kedatangannya mengganggu pertemuaan. Karena itu JT meminta maaf sebelum memberikan laporan. Kalimat yang menyatakan permintaan maaf sebagai salah satu bentuk ekspresi kesantunan dapat dilihat pada (1), Lepat Nyumun sib pangapunten Ndalem, Kanjeng Ratu.... Kesantunan berbahasa dalam kalimat tersebut juga terlihat dari penggunaan sapaan Ndalem dan Kanjeng Ratu.

Pada [8] konteks ujarannya adalah KRK mendatangi Alas Mentaok dan di sana menemukan DS yang sedang bersemedi. Mereka berkenalan dan KRK minta maaf karena baru kali itu tahu Raden Sutawijaya. Pernyataan minta maaf KRK sebagai bentuk kesantunan berbahasa dapat dilihat pada ujaran (1) Oh.... Nyuwun pangapunten... dados Njenengan ingkang asma Raden Sutawijaya? Selain menggunaan permintaan maaf, kesantunan berbahasa dalam ujaran tersebut ditandai dengan penggunaan bentuk sapaan Njenengan dan penggunaan gelar kebangsawanan, Raden.

4) Bentuk SUBDek dalam Tindak Tutur Ekspresif Memuji

Dalam wacana dialog Ketoprak Sapta Mandala Lakon Babad Alas Mentaok, bentuk SUBDek dalam tindak tutur ekspresif memuji dapat dilihat pada data berikut.

[9] KP : Gawe gembira lan mongkok nggih Kang Juru. (1)

(Membuat gembira dan bangga ya Kang Juru)

KJM : Pripun? (2) (Bagaimana?)

KP : Para sanak kadang padesan kok nggih padha grengseng.... (3) (Para saudara dari desa kok ya semua semangat)

KJM : Heh... heh... Mbonten nyana lo Kang, putra Ndika Sutawijaya nike jan wis weh.... mboten wegig kridaning perang mawon niku Di... tetela nggih wasis ngimpun para sanak padesan. (4) (Heh... heh tidak mengira lo Kang, putramu Sutawijaya itu wah... tidak hanya terampil olah perang saja Di... ternyata juga terampil mengatur orang-

Jurnal Budaya Nusantara Vol. 1 No. 2 | 156 
rang desa.)

(BAM.5.3-6)

[10] KRK : Menawi Panjenengan wani... eh... kula trimab kawon Raden. (1)

(Kalau Anda berani... eh..., saya lebih baik mengalah Raden)

DS : Kanjeng Ratu... trimah kawon menika sejatosipun mboten kawon Kanjeng Ratu.... (2)

(Kanjeng Ratu.... lebih baik mengalah itu sebenarnya tidak kalah Kanjeng Ratu....)

KRK : Panjenengan lantip laras kalih pasuryan Panjenengan. (3) Jumbub kalih polatan Penjenengan ingkang wingit nanging ketingal alus pindha bludru. (4)

(Anda cerdas selaras dengan raut muka Anda. Sesuai dengan yang perilaku Anda yang berwibawa tetapi kelihatan halus seperti beludru)

(BAM.6.60-52).

Pada [9], konteks ujarannya adalah KP menyampaikan perasaannya kepada KJM. Dia merasa senang karena anaknya DS mampu mengajak warga desa untuk ikut bergotong royong membabad hutan. Inisiasi $\mathrm{KP}$ tersebut direspon oleh KJM dengan memberikan pujian. Bentuk SUBDek dalam tindak tutur ekspresif memuji dalpat dilihat pada (4) Heh... heh... Mbonten nyana lo Kang, putra Ndika Sutawijaya nika jan wis weh.... mboten wegig kridaning perang mawon niku Di... tetela nggih wasis ngimpun para sanak padesan. Dalam ujaran (4) KJM memuji DS putra $\mathrm{KP}$ tidak hanya pandai berperang (wegig kridaning perang)tetapi juga pandai mengatur warga desa (wasis ngimpun para sanak padesan). Kesantunan ujaran pada [9] ditandai dengan penggunaan strategi pemberian pujian oleh KJM kepada putera KP.

Konteks ujaran [10] adalah KRK berusaha mengalah kepada DS ketika terjadi salah paham karena DS membabad hutan Mentaok tanpa meminta izin terlebih dahulu kepada KRK. Ketika DS mengatakan bahwa mengalah itu berbeda dengan kalah pada ujaran (2), KRK meresponnya dengan pujian pada ujaran (3) dan (4), Panjenengan lantip laras kalih pasuryan Panjenengan.Jumbuh kalih polatan Penjenengan ingkang wingit nanging ketingal alus pindha bludru. Dalam ujaran tersebut KRK memuji DS seorang laki-laki yang cerdas dan memiliki perilaku yang sangat halus. Ujaran tersebut merupakan bentuk BSUDek dalam tindak tutur ekspresif memuji. Seperti halnya pada data [9], pada [10] kesantunan ujaran ditunjukkan dengan memberikan pujian KRK terhadap DS.

5) Bentuk SUBDek dalam Tindak Tutur Ekspresif Mengkritik

Dalam wacana dialog Ketoprak Sapta Mandala lakon Babad Alas Mentaok, bentuk SUBDek dalam tindak tutur ekspresif mengkritik dapat dilihat pada data berikut.

[11] DS : Nanging gegamanmu ki digawa. (1) Ora mek kok diselehke wae. (2) La iki kepiye ta Kang... (3) (Ini senjatamu ini kamu bawa. Tidak hanya ditaruh saja. Kamu ini bagaimana ta Kang....) 
LK 2 : Mengke lek sampun kula ginakaken mesti kula cepeng. (4) Dereng saweg nampi dawnb kok... (5)

(Nanti jika saya gunakan pasyi saya pegang. Belum menerimaperintah kok) (BAM.4.13-14)

[12] DS : Saged kemawon Panjenengan ngendika kados mekaten Kanjeng Ratu... (1) Ing jagat menika kathah perkawis ingkang saged damel alesan.(2) Nanging Panjenengan tetela mboten kagungan watak perwira Kanjeng Ratu. (3)

(Bisa saja Anda mengatakan seperti itu Kanjeng Ratu.... Di dunia ini banyak hal yang dapat dijadikan alasan. Tetapi ternyata Anda tidak mempunyai watak perwira Kanjeng Ratu)

KRK : Oh... heh... heh.... buktinipun Raden? (4)

(Oh... heh... heh... buktinya apa Raden?)

DS : Lekas Panjenengan gampil santun slaga. (5) Sekawit Panjenengan duka amargi rumaos kesenggol kawibawanipun. (6) Nanging wusananipun saksampunipun abon ajeng kalih tiyang ingkang ndamel dukane penggalih Panjenengan, Panjenengan Ndalem malih mboten wani.(7)

(Perilaku Anda gampang berubah-ubah. Semula Anda marah karena merasa tersentuh kewibaan Anda. Tetapi akhirnya setelah berhadapan dengan orang yang membuat Anda Marah, Anda lalu tidak berani.

(BAM.6.67-69)
Pada [11] konteks ujarannya adalah DS memberikan kritik terhadap laki-laki yang membantunya membabat hutan karena tidak bekerja dengan sungguh-sungguh. Kritik DS tersebut dapat dilihat pada ujaran (1)-(3) berikut. Nanging gegamanmu ki digawa. (1) Ora mek kok diselebke wae. (2) La iki kepiye ta Kang... (3) Pada ujaran tersebut DS mengkritik agar peralatan untuk membabad hutan tidak hanya ditaruh saja, tetapi harus digunakan sebagaimana mestinya. Meskipun tindakan mengkritik dapat mengancam muka Pt, dalam ujaran tersebut DS menggunakan bentuk sapaan Kang sehingga dapat mengurangi daya restriksi terhadap pengancaman muka Pt. Dengan penggunaan bentuk sapaan tersebut ujaran DS menjadi terasa santun meskipun DS memberikan kritikan.

Pada [12] konteks ujarannya adalah DS mengkritik KRK karena gampang berubah sikap ketika berhadapan dengan DS. Kritik yang diberikan oleh DS tersebut merupakan realisasi bentuk BSUDek dalam tindak tutur ekspresif mengkritik. Pada ujaran (3) DS mengkritik KRK tidak memiliki watak ksatria. Hal ini tampak pada ujaran DS berikut, Nanging Panjenengan tetela mboten kagungan watak perwira Kanjeng Ratu (3), sedangkan pada ujaran (5) DS mengkritik KRK gampang berubah pikiran (Lekas Panjenengan gampil santun slaga). Kesantunan ujaran dalam [12] ditandai dengan penggunaan bentuk sapaan Panjenengan dan Kanjeng Ratu sebagai bentuk penghormatan sehingga kritik yang diberikan tidak terlalu mengancam muka Pt. 


\subsubsection{Bentuk SUBInt}

Ujaran bermodus interogatif memunyai maksud untuk menanyakan sesuatu kepada Pt. (Rahardi, 2000 dan Alwi, dkk., 2000). Bentuk SUBInt dalam wacana dialog Ketoprak Sapta Mandala lakon Babad Alas Mentaok direalisasikan dalam tindak tutur direktif meminta penjelasan, mengonfirmasikan, dan meminta izin. Masing-masing realisasi tindak tutur dipaparkan berikut.

1) Bentuk SUBInt dalam Tindak Tutur Direktif Meminta Penjelasan

Penggunaan bentuk SUBInt dalam tindak tutur direktif meminta penjelasan dapat dilihat pada [13] dan [14] di bawah ini.

[13] KP : Dos pundi Kang Juru? (1)

(Bagaimana Kang Juru)

KJM : Angger Sutawijaya kedhah wani mesu sarira. (2)

(Ananda Sutawijaya harus berani prihatin)

DS : Nun injih.... Wo injih.... (3)

(Iya... Iya Paman) (BAM.5.71-73)

[14] DS : Sebabipun menapa Kanjeng Ratu Kidul madosi kula menika? (1)

(Sebabnya apa Kanjeng Ratu Kidul mencari saya?)

KRK : Raden Sutawijaya kedhah mangertos. (2) Kenging menapa Panjenengan mlebet alas Mentaok... (3)

(Raden Sutawijaya seharusnya mengerti. Tetapi mengapa Anda masuk Alas Mentaok....)

DS : Heh....(4)

KRK : Babat-babat wana mboten mundhut palilah kula? (5)
(Membabati hutan tidak minta izin saya dulu.)

(BAM.6.41-44)

Konteks ujaran [13], KP meminta penjelasan kepada KJM tentang apa yang harus dilakukan oleh DS untuk mengatasi permasalahan harus dihadapi ketika membabat hutan Mentaok. Seperti diceritakan ketika sedang membabat hutan Mentaok, Sutawijaya dan para warga yang membantu mendapatkan gangguan dari para mahkluk halus prajurit Laut Selatan. Tindak tutur interogatif meminta penjelasan dapat dilihat pada ujaran (1) Dos pundi Kang Juru? Inisiasi KP tersebut direspon oleh KJM dengan memberikan petunjuk agar DS berani melakukan tapa brata untuk menghadapi para lelembut. Hal ini dapat dilihat pada ujaran (2) Angger Sutawijaya kedhah wani mesu sarira. Petunjuk KJM tersebut dipatuhi oleh DS dengan mengatakan, Nun injih.... Wo injih.... Kesantunan berbahasa dalam [13] ditandai dengan penggunaan bentuk sapaan Kang dan ragam krama dalam ujaran KP dan bentuk sapaan angger dalam ujaran KJM.

Konteks ujaran [14], KRK menemui DS di hutan Mentaok karena akibat perbuatan DS mengganggu ketenteraman Laut Kidul. DS yang sedang membabat hutan Mentaok dianggap mengganggu kedaulatan Kerajaan Laut Selatan. Bentuk SUBInt dalam tindak tutur meminta penjelasan dapat dilihat pada ujaran (1) Sebabipun menapa Kanjeng Ratu Kidul madosi kula menika? Dalam ujaran tersebut DS bertanya mengapa KRK mencari DS. Inisiasi DS tersebut direspon oleh KRK dengan pertanyaan, mengapa DS 
tidak meminta izin terlebih dahulu sebelum membabat hutan Mentaok karena hutan tersebut di bawah kekuasaan Ratu Kidul. Hal ini dapat dilihat pada ujaran (2), Raden Sutawijaya kedhah mangertos. (3), Kenging menapa Panjenengan mlebet alas Mentaok... dan (5) Babat-babat wana mboten mundhut palilah kula? Kesantunan berbahasa pada [14] ditandai dengan penggunaan bentuk sapaan hormat raden sebagai gelar kebangsawanan dan panjenengan .

2) Bentuk SUBInt dalam Tindak Tutur Direktif Mengonfirmasikan

Bentuk SUBInt dalam tindak tutur direktif mengonfirmasikan dalam wacana dialog Ketoprak Sapta Mandala lakon Babad Alas Mentaok dapat dilihat pada data berikut.

[15] DS : Kanjeng Ratu duka sake estu, injih? (1)

(Kanjeng Ratu marah beneran, iya?)

KRK : Heh.... Pancenipun. (2) Sareng kawula manah sakestu kula sampun mlebet dateng pancingan Panjenengan supados kula nesu. (3) Ngheh.... mila menawi ingkang ngina Penjenengan kula raos mboten dados menapa. (4) Malah... malah tiwas keleresan Raden. (5)

(Heh... sebenarnya iya. Tetapi serelah saya renungan sebenarnya saya telah masuk dalampancingan supaya saya marah. Ngheh... tapi kalau yang menghina Anda saya rasa tidak apa-apa. Malah kebetulan Raden.) (BAM.5.79-80)
[16] DS : Lho... Wo Juru Mertani nimbali kula Wo? (1)

(Lho.... Paman Juru Mertani memanggil saya paman?)

KJM : Heh... heh... heh.... Lha wong kula sumerep Angger pepanggiban kalib Ratu Kidul, nggih ta? (2)

(Heh... heh... heh... Lha saya kan tahu Ananda bertemu dengan Ratu Kidul, iya kan?)

DS : Wo Juru priksa, injih? (3)

(Paman Juru mengetahui ya?)

KJM : Lha... semerep mawon kok. Ratu Kidul kedanan Angger, nggih ta? (4)

(Lha tahu aja. Ratu Kidul tergilagila kepada Ananda kan?)

DS : Inggih Wo.... Inggih. (5)

(Iya Paman... iya.)

(BAM.7.9-13)

Konteks ujaran [15], DS melakukan konfirmasi kepada KRK apakah benar-beanr marah karena DS telah membabat hutan Mentaok tanpa izin kepada KRK. Ujaran DS pada (1), Kanjeng Ratu duka sak estu, injih? merupakan bentuk SUBInt dalam tindak tutur interogatif mengonfirmasikan. Inisiasi yang dilakukan oleh DS direspon oleh KRK dengan menyatakan bahwa seharusnya KRK marah tetapi KRK menyadari bahwa upaya membuatnya marah itu merupakan pancingan DS sehingga KRK tidak mau masuk dalam siasat DS agar dia marah. Meskipun DS menghina dirinya, KRK justru merasa senang. Hal ini terjadi karena KRK memang sangat tertarik dan jatuh hati kepada DS. Kesantunan berbahasa dalam data [15] ditandai dengan penggunaan sapaan kanjeng ratu oleh DS dan bentuk sapaan panjenengan oleh KRK. 
Pada [16], konteks ujarannya adalah KJM memanggil DS dan meminta penjelasan tentang pertemuan DS dengan KRK. DS kaget karena pertemuannya dengan KRK diketahui oleh KJM. Bentuk SUBInt dalam tindak tutur direktif mengonfirmasikan dapat dilihat pada ujaran (1) Lho... Wo Juru Mertani nimbali kula Wo? Pada ujaran tersebut DS mengonfirmasikan apakah KJM memanggilnya. Pada ujaran (3) Wo Juru priksa, injih?, DS mengonfirmasikan apakah KJM mengetahui pertemuannya dengan KRK. Pertanyaan DS tersebut direspon oleh KJM dengan melakukan konfirmasi kalau KRK jatuh cinta kepada DS. KJM menyatakan dalam (4), Ratu Kidul kedanan Angger, nggih ta? Hal tersebut kemudian direspon oleh DS dengan mengiyakan Inggih Wo.... Inggih pada ujaran (5). Kesantunan berbahasa dalam data [16] ditandai dengan penggunaan sapaan wo oleh Ds dan penggunaan sapaan angger oleh KJM.

3) Bentuk SUBInt dalam Tindak Tutur Direktif Meminta Izin

Dalam wacana dialog Ketoprak Sapta Mandala lakon Babad Alas Mentaok bentuk SUBInt dalam tindak tutur direktif meminta izin dapat dilihat pada data [17] dan [18] berikut.

[17] Jim : Kanjeng Ratu.... Nyuwun sib pangapunten Ndalem... Keparengan kula badhe munjuk Kanjeng Ratu.... (1)

(Kanjeng Ratu.... mohon ampun Paduka. Perkenankan saya mau melapor Kanjeng Ratu...)

KRK : Wah... beh... heh.... Ho ob. Iya... iya.... Coba munjuka kowe! (2)
(Wah.... heh... heh... ho oh iya... iya. Silakan kamu melapor)

(BAM.3.38-39)

[18] DS : Menawi kedhah mekaten lampabipun Wo... Amrib mboten kedangon kula nyuwun pamit! (1) (Kalau harus demikian Paman... biar tidak kelamaan saya mohon pamit!)

KJM : Inggih... Inggih Ngger... kula dongake mawon saking tebihan. (2) (Iya... iya Ananda. Saya doakan saja dari kejauhan).

DS : Sampun nggih Wo.... (3)

(Sudah ya Paman....)

(BAM.5.75-77)

Pada [17] konteks ujarannya adalah Jim Trabela meminta izin kepada KRK untuk melaporkan keadaan di hutan Mentaok. Tindak tutur direktif meminta izin dapat dilihat pada ujaran (1) Kanjeng Ratu... Nyuwun sib pangapunten Ndalem... Keparengan kula badhe munjuk Kanjeng Ratu.... Permintaan izin tersebut direspon KRK dengan memerintahkan Jim Trabela untuk melapor. Hal ini dapat dilihat pada ujaran (2), Wah... beh... heh... Ho... oh. Iya... iya... Coba munjuka kowe! Kesantunan berbahasa dalam [17] ditandai dengan penggunaan sapaan Kanjeng Ratu oleh Jim Trabela kepada KRK.

Konteks ujaran [18] adalah DS meminta izin kepada KJM untuk segera melakukan apa yang disarankan oleh KJM. KJM menyarankan kepada DS untuk bertapa dalam mengatasi gangguan para lelembut dalam membabat alas Mentaok. Tindak tutur direktif meminta izin tersebut dapat dilihat pada ujaran (1), Menawi kedhah mekaten lampabipun Wo... Amrih mboten 
kedangon kula nyuwun pamit! Permintaan izin DS tersebut direspon KJM dengan memberikan izin dan mendoakan DS dari kejauhan. Respon KJM tersebut dapat dilihat pada ujaran (2), Inggih... Inggih Ngger... kula dongake mawon saking tebihan. Kesantunan berbahasa dalam [18] ditandai dengan penggunaan bentuk sapaan wo dan ragam krama oleh DS kepada KJM.

\subsubsection{Bentuk SUBImp}

Menurut Rahardi (2000) dan Alwi, dkk. (2000), ujaran bermodus imperatif dalam bahasa Indonesia mengandung maksud ajakan, perintah, permintaan atau permohonan agar $\mathrm{Pt}$ melakukan sesuatu seperti yang diinginkan oleh Pn. SUBImp dalam dialog Ketoprak Sapta Mandala lakon Babad Alas Mentaok direalisasikan dalam tindak tutur direktif memerintah, menyilakan, melarang, dan. Masing-masing realisasi tindak tutur dipaparkan sebagai berikut.

1) Bentuk SUBImp dalam Tindak Tutur Direktif Memerintah

Dalam wacana dialog Ketoprak Sapta Mandala lakon Babad Alas Mentaok, bentuk SUBImp dalam tindak tutur direktif memerintah dapat dilihat pada [19] dan [20] berikut.

[19] KJM : Niku kanca-kanca sing anu.... gawane Cakera njur kabeh dijak... Niki mangke maju... (1)

(Itu teman-teman yang anu... dibawa oleh Cakra segera diajak... Ini nanti maju....)

LK1 : Njur kula bagian sisib pundi ngaten? (2) Wetan napa sib kulon? (3)

(Lalu saya bagian yang mana? Timur apa yang sebelah barat?)

KP : Saiki kowe sisib wetan! Cakra saka sisih kidul! Aku mengko saka sisib kulon! (4)

(Sekarang kamu bagian timur! Cakra dari sisi selatan! Aku nanti dari sisi barat!)

DS : Saiki kanca-kanca budhal sakniki! (5)

(Sekarang teman-teman berangkat sekarang!)

KP : Monggo! Monggo!

(BAM.2.41-45)

(Silakan! Silakan!)

[20] KRK : Miturut pelapurane Jim Trabela iki ana cabya manther. (1)

(Menurut laporan Jim Trabela ini ada cahaya terang)

MRK : Injih.... (2)

(Iya...)

KRK : Iki mesthi ana apa-apa. (3) Mula aku mundhut tata-tataa! (4) Sametakna para prajurit! (5) Dawnhna nderek tindak. Ingsun Mbok Rara....! (6)

(Ini pasti ada apa-apa. Karena itu aku minta bersiap-siaplah. Siagakan para prajurit. Perintahkan mengiringi kepergianku Mbok Rara)

MRK : Sendika Kanjeng Ratu..... (7)

(Siap Kanjeng Ratu....)

(BAM.3.59-62)

Konteks ujaran [19], KJM, KP, dan DS bersama-sama warga desa akan memulai membabat hutan Mentaok. Para pemimpin tersebut mengatur pembagian tugas kepada para warga. Bentuk SUBImp dalam tindak tutur memerintah pada [19] dapat dilihat pada ujaran 
(1), (4), dan (5). Pada ujaran (1), Niku kancakanca sing anu... gawane Cakra njur kabeh dijak... Niki mangke maju... KJM memerintah orangorang yang diajak oleh Cakra untuk maju. Pada ujaran (4), Saiki kowe sisib wetan! Cakera saka sisib kidul! Aku mengko saka sisih kulon! KP melakukan pembagian tugas kepada Cakra dan teman-temannya, sedangkan pada ujaran (5), Saiki kanca-kanca budhal sakniki! DS memerintahkan kepad semua warga untuk berangkat ke hutan sekarang. Kesantunan ujaran dalam [19] ditandai dengan penggunaan ragam krama oleh para pemimpin kepada bawahannya. Hal ini menunjukkan bahwa mereka menghargai orang-orang yang secara suka rela ikut membantu membabat hutan Mentaok.

Pada [20], konteks ujarannya adalah KRK setelah mendapatkan laporan dari Jim Trabela memerintahkan kepada MRK untuk menyiapkan prajurit untuk mengikuti KRK yang akan melihat situasi di hutan Mentaok. Penggunaan SUBImp dalam tindak tutur memerintah dapat dilihat pada ujaran (4), (5), dan (6) sebagai berikut. Mula aku mundhut tata-tataa! (4) Sametakna para prajurit! (5) Dawubna nderek tindak Ingsun Mbok Rara...! (6) Kalimat-kalimat tersebut diujarkan oleh seorang ratu kepada patihnya sehingga penggunaan perintah secara langsung tersebut dapat dikategorikan sebagai ujaran yang santun. Perintah tersebut direspon oleh MRK dengan mematuhi perintah, Sendika Kanjeng Ratu.... pada ujaran (7).
2) Bentuk SUBImp dalam Tindak Tutur Direktif Menyilakan

Dalam wacana dialog Ketoprak Sapta Mandala lakon Babad Alas Mentaok, bentuk SUBImp dalam tindak tutur direktif menyilakan dapat dilihat pada [21] dan [22] berikut.

[21] KJM : Mosok kula tega kalih Njenengan kalih Angger Danang. (1) Pun Di... Ampun kedangon sakniki becike terus budhal! (2) (Masak saya tega dengan Adi dan Ananda Danang. Sudah Di... jangan sampai kelamaan. Sekarang sebaiknya terus berangkat!)

KP : Nggih... nggih. (3)

(Iуа... Iуа....)

DS : Monggo Wo... monggo. Monggo kula derekaken. Monggo... Monggo Wo.... (4)

(Mari Paman... Mari.... saya antarkan. Mari... Mari... Paman) (BAM.1.97-99)

KRK : Menika cobi... kula aturi mriksani sisib kilen menika! (5) Sajakipun Panjenengan dipun aturi tiyang sepuh. (6) Eh... monggo kula aturi jengkar rumiyin Raden! (7)

(Itu coba... saya silakan melihat bagian barat itu. Sepertinya Anda dipanggil oleh orang tua. Eh... saya silakan pergi dulu Raden)

DS : Injih... injih... Kanjeng Ratu injih. (8)

(Iya... Iya.... Kanjeng Ratu....)

KRK : Monggo... monggo....

(BAM.6.104-106)

(Silakan.... silakan.)

Konteks ujaran [21], DS menyilakan KJM untuk berangkat bersama menuju hutan 
Mentaok. Mereka memutuskan segera berangkat setelah menyepakati untuk membabat hutan Mentaok. Bentuk SUBInp dalam tindak tutur direktif menyilakan dapat dilihat pada ujaran (3) Monggo Wo... monggo. Monggo kula derekaken. Monggo... Monggo Wo.... Kesantunan ujaran DS tersebut ditandai dengan bentuk silaan dengan menggunakan ragam krama, monggo.

Pada [22] konteks ujarannya adalah KRK menyilakan DS untuk menemui KJM dan KP setelah mereka berdialog persoalan hutan Mentaok dan pribadi mereka. Bentuk SUBInp dalam tindak tutur direktif menyilakan dapat dilihat pada ujaran (5), Menika cobi... kula aturi mriksani sisih kilen menika! dan (7), Eh... monggo kula aturi jengkar rumiyin Raden! Kesantunan berbahasa dalam kalimat tersebut ditandai dengan penggunaan ragam krama oleh KRK kepada DS dan penggunaan bentuk sapaan dengan menyebut gelar bangsawan, raden.

3) Bentuk SUBImp dalam Tindak Tutur Direktif Mengajak

Dalam wacana dialog Ketoprak Sapta Mandala lakon Babad Alas Mentaok, bentuk SUBImp dalam tindak tutur direktif mengajak dapat dilihat pada [23] berikut.

[23] DS : Mulane kumi kanthi ati kang suci, aja dhuweni karep kang wernawerna, ayo padha tumandang gawe! (1)

(Karena itu dengan hati yang suci, jangan mempunyai keinginan yang macam-macam, ayo segera bekerja!)
LK 1 : Oh... injï.... (2) (BAM.3.9-10)

(Oh... iya)

Konteks ujaran [23] adalah DS menasihati warga yang akan membantu membabat hutan Mentaok agar mempunyai hati yang suci dan tidak mempunyai keinginan yang bermacammacam sebelum bekerja. SUBImp dalam tindak tutur direktif mengajak dapat dilihat pada kalimat (1), Mulane kuni kanthi ati kang suci, aja dhuweni karep kang werna-werna, ayo padha tumandang gawe! Kesantunan berbahasa dalam ujaran tersebut ditandai dengan penggunaan bentuk ajakan, ayountuk memperlunak daya restriksi. Ujaran tersebut dapat dianggap sebagai ujaran yang santun karena diujarkan oleh seorang putera raja kepada rakyatnya.

4) Bentuk SUBImp dalam Tindak Tutur Direktif Memohon

Dalam wacana dialog Ketoprak Sapta Mandala lakon Babad Alas Mentaok, bentuk SUBImp dalam tindak tutur direktif memohon dapat dilihat pada [24] dan [25] berikut.

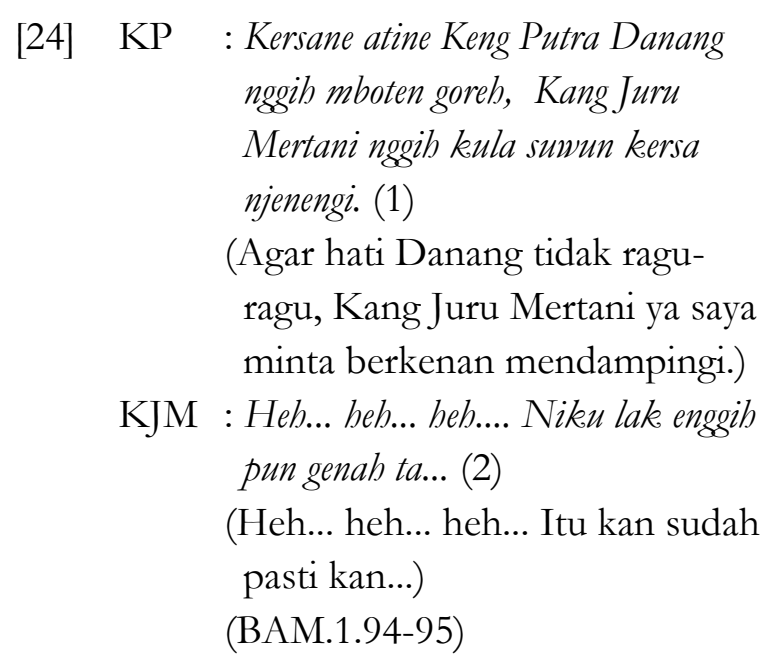


[25] KP : Mboten Kang Juru... terus igube Kang Juru awake dhewe niku mangke apike kados pripun? (1)

(Maaf Kang Juru.... lalu sarana Kang Juru kita itu sebaiknya bagaimana?)

KJM : Heh.... buk... buk (suara terbatukbatuk). Niki petung kula niki. (2)

(Heh.... huk... huk. Ini perhitungan saya ini)

$\mathrm{KP} \quad$ : Enggih.... (3)

(Iya....)

KJM : Adi Pemanahan jumeneng ndisik.

(Adi Pemanahan menobatkan diri dulu.)

(BAM.5.35-38)

5) Bentuk SUBImp dalam Tindak Tutur Direktif Mengingatkan

Dalam wacana dialog Ketoprak Sapta Mandala lakon Babad Alas Mentaok, bentuk SUBImp dalam tindak tutur direktif mengingatkan dapat dilihat pada [26] dan [27] berikut.

\footnotetext{
MRK : Kanjeng Ratu.... ob Kanjeng

Ratu.... nyuwun gunging pangapunten Ndalem. (1) Emut!

Emut! Kanjeng Ratu....(2)

(Kanjeng Ratu.... oh Kanjeng Ratu... mohon maaf yang sebesar-besarnya dari Paduka. Sadar! Sadar! Kanjeng Ratu....)

KRK : Eh.... Ingsun diaturi emut? (3) Ingsun iki mbok anggep ora emut ngono Mbok Rara Kidul? (4) Eh... He...eh. Ingsun iki sib emut jare.

(Eh... saya diminta sadar? Saya ini kamu kira tidak sadar begitu Mbok Rara Kidul? Eh... he... eh. Saya ini masih sadar).

(BAM.3.1-2)
}

[27]

DS : Wis ya.... kulon karo wetan tumandhang kabeh! (1)

(Sudah ya... Yang Barat dan Timur bekerja semua!)

LK 1 : Inggih.... (2)

(Iya....)

DS : Ning jo nggugu karepe dhewe lo ya!

(3) Iki papan kang werit. (4)

(BAM.4.37-39)

(Tapi jangan seenaknya sendiri ya!. Ini tempat yang angker.)

Konteks ujaran [26] adalah MRK mengingatkan KRK karena KRK hanyut dalam perasaaan asmaranya. Dalam penilaian MRK, KRK yang berkidung menyatakan asmaranya akan dapat mengurangi kewibawaan dan keharuman namanya sebagai penguasa Laut Selatan. BSUBImp dalam tindak tutur direktif mengingatkan dapat dilihat pada ujaran (2) Emut! Emut! Kanjeng Ratu.... Kesantunan berbahasa dalam [26] ditandai dengan penggunaan ragam krama oleh MRK dan permohonan maaf sebelum MRK mengingatkan KRK.

Dalam [27], konteks ujarannya adalah DS mengingatkan para warga untuk tindak bertindak seenaknya sendiri dan memberitahukan bahwa hutan Mentaok adalah tempat yang sangat angker. BSUBImp dalam tindak tutur direktif mengingatkan dapat dilihat pada kalimat (3), Ning jo nggugu karepe dhewe lo ya! Ujaran tersebut tetap dianggap sebagai ujaran yang santun karena dituturklan oleh DS sebagai putera raja kepada rakyatnya. 
6) Bentuk SUBImp dalam Tindak Tutur Direktif Meminta izin

Dalam wacana dialog Ketoprak Sapta Mandala lakon Babad Alas Mentaok, bentuk SUBImp dalam tindak tutur direktif meminta izin dapat dilihat pada [28] dan [29] berikut.

[28] MRK : Wonten kepareng Ndalem kula munjuk Kanjeng Ratu? (1)

(Mohon perkenan Paduka saya bertanya Kanjeng Ratu?)

KRK : Arep munjuk apa Mbok Rara Kidul? (2)

(Mau tanya apa Mbok Rara Kidul?)

MRK : Lepat nyuwun sib pangapunten Ndalem. (3)

(Sekiranya salah mohon pengampuanan Paduka).

KRK : He...eh. (4)

(He... eh).

MRK : Menapa inggih leres menawi Sampean Ndalem saweg ginubel ing raos asmara Kanjeng Ratu? (5) (BAM.3.11-15)

(Apa memang benar Paduka sedang diliputi rasa asmara Kanjeng Ratu?)

[29] DS : Menawi kedhah mekaten lampahipun Wo... Amrib mboten kedangon kula nyumun pamit. (1) (Kalau memang demikian yang harus dijalani Paman... agar tidak terlalu lama saya mohon pamit.)

KJM : Inggih... Inggih Ngger... kula dongake mawon saking tebihan. (2) (BAM.5.75-76) (Iya... iya... Ananda... saya doakan dari kejauhan.)
Konteks ujaran [28] adalah MRK ingin mengetahui kondisi yang sedang dialami oleh KRK. Untuk itu sebelum bertanya, MRK memohon izin kepada KRK. Sebagai seorang patih, tentu MRK tidak berani bertanya secara langsung sebelum mendapatkan izin dari KRK. BSUBImp dalam tindak tutur direktif memohon izin dapat dilihat pada ujaran (1), Wonten kepareng Ndalem kula munjuk Kanjeng Ratu? Kesantunan berbahasa dalam ujaran tersebut ditandai dengan penggunaan ragam krama oleh WRK dan penggunaan sapaan penghormatan ndalem.

Pada data [29], konteks ujarannya adalah DS memohon izin kepada KJM untuk segera melakukan apa yang disarankan oleh KJM yaitu melakukan tapa brata di hutan Mentaok. BSUBImp dalam tindak tutur direktif meminta izin dapat dilihat pada ujaran (1) Menawi kedhah mekaten lampahipun Wo... Amrih mboten kedangon kula nyunun pamit. Kesantunan berbahasa dalam ujaran tersebut ditandai dengan penggunaan ragam krama dan penggunaan bentuk sapaan wo oleh DS kepada KJM.

7) Bentuk SUBImp dalam Tindak Tutur Direktif Menyarankan

Dalam wacana dialog Ketoprak Sapta Mandala lakon Babad Alas Mentaok, bentuk SUBImp dalam tindak tutur direktif menyarankan dapat dilihat pada [30] dan [31] berikut.

[30] KJM : Mula nek igub kula... (1) (Karena itu saran saya....)

KP : Dospundi? (2)

(Bagaimana....) 
KJM : Dibabat mawon pun sakniki Alas

Mentaok! Dibabat...! (3)

(Dibabat saja sekarang Alas

Mentaok! Dibabat!)

(BAM.1.75-77)

[31]

KJM : Pun...pun niki lakon sing apik banget jenenge. (1) Iguh kula ditampi mawon nggih... Katresanane Kanjeng Ratu Kidul nik.u.... (2)

Ning nggib niku waton gelem mbiyantu olehe awake dhewe gawe negara niki Ngger.(3)

(Sudah... sudah... ini lakon yang baik sekali namanya. Ssaran saya diterima saja ya.... cintanya Kanjeng Ratu Kidul. Tetapi ya itu asal mau membantu citacita kita membangun negara Ananda....)

DS : Ngaten kersanipun Wo Juru Mertani? (4) (BAM.7.14-15) (Begitukah kemauan Paman Juru Mertani?)

Konteks ujaran [30] adalah KJM memberi saran atas permintaan KP dalam menyikapi perkara hutan Mantaok yang oleh Sultan Hadiwijaya sampai sat itu belum juga diberikan. KJM menyarankan agar hutan Mentaok tersebut segera dibabat saja. BSUBImp dalam tindak tutur direktif menyarankan dapat dilihat pada ujaran (1), Mula nek igub kula..., (3) Dibabat mawon pun sakniki Alas Mentaok! Dibabat...! Kesantunan berbahasa dalam ujaran tersebut ditandai dengan penggunaan ragam krama oleh KJM. Hal ini menunjukkan kalau KJM menghormati KP sebagai adik seperguruannya.

Konteks ujaran [31], KJM memberikan sarana kepada DS untuk menerima cinta KRK.
KJM mengetahui kalau KRK jatuh cinta kepada DS. KJM menyarankan kepada DS untuk memberikan persyaratan yaitu asal KRK mau membantu perjuangan DS dalam membabat hutan Mentaok dan mendirikan kerajaan Mataram. BSUBImp dalam tindak tutur direktif menyarankan dapat dilihat pada ujaran (2) Iguh kula ditampi mawon nggih... katresanane Kanjeng Ratu Kidul niku.... Kesantunan berbahasa dalam ujaran tersebut dapat dilihat dari penggunaan ragam krama oleh KJM kepada DS. Hal ini dilakukan karena KJM menyadari kalau DS adalah putera angkat seorang raja.

\section{KESIMPULAN}

Berdasarkan hasil analisis data dapat disimpulkan bentuk ujaran yang merepresentasikan kesantunan berbahasa dibedakan atas bentuk kesantunan ujaran bermodus deklaratif (SUBDek), bentuk kesantunan ujaran bermodus interogatif (SUBInt), dan bentuk kesantunan ujaran bermodus imperatif (SUBImp). Bentuk SUBDek dalam wacana Ketoprak Sapta Mandala Lakon babad Alas Mentaok direalisasikan dalam berbagai bentuk tindak tutur. Keragaman tindak tutur tersebut meliputi (1) tindak tutur asertif memberitahukan dan menyatakan; dan (2) tindak tutur ekspresif menyampaikan terima kasih, menyatakan rasa senang, meminta maaf, memuji, dan mengkritik. Bentuk SUBInt dalam wacana dialog Ketoprak Sapta Mandala lakon Babad Alas Mentaok direalisasikan dalam tindak tutur direktif meminta penjelasan, mengonfirmasikan, dan 
meminta izin. SUBImp dalam dialog Ketoprak Sapta Mandala lakon Babad Alas Mentaok direalisasikan dalam tindak tutur direktif memerintah, menyilakan, melarang, dan mengajak.

\section{DAFTAR PUSTAKA}

Allen, D. E. \& Guy, R.F.

1974. Conversational Analysis: The Sociology of Talk. Paris: Mouton.

Alwi, H., dkk.

2000.Tata Bahasa Baku Bahasa Indonesia (Edisi Ketiga). Jakarta: Balai Pustaka.

Aziz, E.A.

2003. "Usia dan Realisasi Kesantunan Berbahasa: Sebuah Studi Pragmatik pada Penutur BI". PELLBA 16.(Penyunting Bambang Kaswanti Purwo). Jakarta: Pusat Kajian Bahasa dan Budaya UNIKA Atmajaya.

Aziz, M.

2012. Tentang Kesenian Ketoprak dan Metamorfosis Kesenian

http://swaramasfm.com/tentang-kesenianketoprak-dan-metamorfosis-kesenian/ diunduh 15 Febuari 2013.

Bogdan, R. C. and Biklen, S.K.

1998. Qualitaive Research for Education: An Introduction to Theory and Methods. Boston: Allyn and Bacon Inc.
Brown, P. dan Levinson, S.C.

1987. Politeness Some Universals in Language Usage. New York: Cambridge University Press.

Coulthard, M.

1985. An Introduction to Discourse Analysis. New York: Longman.

Dhave, D.

2011. Ketoprak, Opera Jawa Penuh Sarat dan Makna http://sosbud.kompasiana.com/2011/1 2/31/ketoprak-opera-jawa-penuh-saratdan-makna-423612.html diunduh 15

Febuari 2013.

Duranti, A.

1997. Linguistic Antrophology. Cambridge: Cambrigde University Press.

Eelen, G.

2001. Kritik Teori Kesantunan (Penerjemah Jumadi dan Slamet Rianto). Surabaya: Airlangga University.

Grice, H.P.

1975. "Logic in Conversation" dalam Syntax and Semantics (P. Cole dan J.L. Morgan Ed.). New York: Academic Press.

Gunarwan, A.

2009. Pragmatik Teori dan Kajian Nusantara. Jakarta: Penerbit Universitas Atmajaya.

Ide, S., dkk. 
1992. "The Concept of Politeness: An Empirical Studi of American English and Japanese", in Richards Watts, Sachico Ide, K. Watts (eds). Politeness in Language: Studies in Its History, Theory and Methods. Boston: Allyn and Bacon, Inc.

Keating, E.

2001. "The Ethnography of Communication" in Handbook of Ethnography (editor Paul Atkinson, et all). Los Angeles: Sage Publications.

Kridalaksana, $\mathrm{H}$.

1984. Kamus Linguistik. Jakarta: PT Gramedia.

Lakoff, R.

1989. "The limits of politeness: therapeutic and courtroom discourse". Multilingua 8(2/3)101-129.

Leech, G.

1993. Prinsip-Prinsip Pragmatik. (Penerjemah M.D.D. Oka.) Jakarta: UI Press.

Levinson, S. C.

1983. Pragmatics. Cambridge: Cambrdge Schiffrin, D. University Press.

Mey, J. L.

1993. Pragmatics: An Introduction. Oxford: Scollon, R. dan Scollon, S.W.

Blackwell Publisher Ltd.
Miles, B.M. dan Huberman, A.M.

1992. Analisis Data Kualitatif Buku Sumber tentang Metode-Metode baru. Terjemahan Tjetjep Rohendi Rohidi. Jakarta: UI Press.

Pramujiono, A.

2008. "Kesantunan Positif Komunikasi DokterPasien dalam Program Konsultasi Seks" dalam Linguistik Indonesia Jurnal Ilmiah Masyrakat Linguistik Indonesia. Tahun ke 26 Nomor 2 hal. 151-167 Agustus 2008.

Rahardi, K.

2000. Imperatif dalam Bahasa Indonesia. Yogyakarta: Duta Wacana University Press.

Richards, J.C. dan Schmidt, R.W.

1983. "Conversational Analysis" dalam Language and Communication (Richards dan Schmidt Ed.). London: Longman.

Saville-Troike, M.

1986. The Ethnography of Communication. New York: Basil Blackwell.

1994. Approach to Discourse. Cambridge: Black Well Publishers.

2001. Intercultural Communication. USA: Blackwell Publishing. 
Sudaryanto.

1993. Metode dan Aneka Teknik Analisis Bahasa.

Yogyakarta: Duta Wacana University Press.

Kuswarno, E.,

2008. Etnografi Komunikasi Suatu Pengantar dan

Contoh Penelitiannya. Bandung: Widya Padjajaran.

Van Dijk, T. A.

1985. "Introduction: Dialogue as Discourse and Interaction." dalam Handbook of Discourse Analysis Volume 3 Discourse and Dialogue. London: Academic Press.

Watts, R.

2003. Politeness. Cambridge: Cambridge University Press. 